\title{
Tips and tricks for a safe and effective image-guided percutaneous renal tumour ablation
}

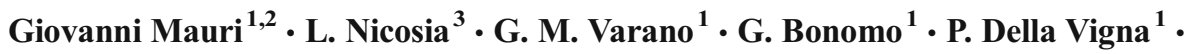 \\ L. Monfardini ${ }^{4} \cdot$ F. Orsi ${ }^{1}$
}

Received: 18 December 2016 / Revised: 8 March 2017 / Accepted: 13 April 2017 /Published online: 12 May 2017

(C) The Author(s) 2017. This article is an open access publication

\begin{abstract}
Image-guide thermal ablations are nowadays increasingly used to provide a minimally invasive treatment to patients with renal tumours, with reported good clinical results and low complications rate. Different ablative techniques can be applied, each with some advantages and disadvantages according to the clinical situation. Moreover, percutaneous ablation of renal tumours might be complex in cases where there is limited access for image guidance or a close proximity to critical structures, which can be unintentionally injured during treatment. In the present paper we offer an overview of the most commonly used ablative techniques and of the most important manoeuvres that can be applied to enhance the safety and effectiveness of percutaneous image-guided renal ablation. Emphasis is given to the different technical aspects of cryoablation, radiofrequency ablation, and microwave ablation, on the ideal operating room setting, optimal image guidance, application of fusion imaging and virtual navigation, and contrast enhanced ultrasound in the guidance and monitoring of the procedure. Moreover, a series of protective manoeuvre that can be used to avoid damage to surrounding sensitive structures is presented. A selection of cases of
\end{abstract}

Giovanni Mauri

vanni.mauri@gmail.com

1 Divisione di Radiologia Interventistica, Istituto Europeo di Oncologia, Via Ripamonti 435, 20141 Milan, Italy

2 Servizio di Radiologia, IRCCS Policlinico San Donato, Piazza Edmondo Malan, San Donato Milanese, Italy

3 Scuola di specializzazione in Radiodiagnostica, Università degli studi di Milano, Via Festa del Perdono 7, Milan, Italy

4 Dipartimento di radiologia e diagnostica per immagini, Poliambulazna di Brescia, Via Leonida Bissolati 57, Brescia, Italy image-guided thermal ablation of renal tumours in which the discussed technique were used is presented and illustrated.

Teaching points

- Cryoablation, radiofrequency and microwave ablation have different advantages and disadvantages.

- US, CT, fusion imaging, and CEUS increase an effective image-guidance.

- Different patient positioning and external compression may increase procedure feasibility.

- Hydrodissection and gas insufflation are useful to displace surrounding critical structures.

- Cold pyeloperfusion can reduce the thermal damage to the collecting system.

Keywords Renal tumours $\cdot$ Renal ablation $\cdot$ Protective manoeuvres $\cdot$ Image-guided tumour ablation $\cdot$ Image guidance

\section{Introduction}

Kidney cancer are among the most prevalent tumours in western countries, with an incidence of 2,9-15 per 100,000 in Europe and 50,000 new cases in the United States each year [1-3]. Conventional treatment has been historically represented by radical nephrectomy, while, more recently, surgical nephron sparing techniques have been developed in order to reduce the invasiveness of the treatment [4-6]. For the same reason, image-guided thermal ablations have been successfully applied in several different organs, including liver, lung, bone, and even neck tumours [5, 7-14]. The necessity to offer a treatment to patients not suitable for surgery, and to spare the highest amount of normal renal parenchyma has pushed for the application of image-guided ablative techniques to renal cancer $[15,16]$ with reported good clinical results [17-19]. 
However, some factors could limit the feasibility and/or safety of these techniques. In particular, the proximity to the tumour of sensitive structures that might be damaged by thermal injury can limit the application of image-guided ablations [20].

The availability of the most advanced imaging techniques, including a dedicated room with computed tomography (CT) and a last generation ultrasound (US) machine, possibly equipped with fusion imaging, may enhance the correct targeting of the tumour and maximize the technical result [21-25]. Furthermore, different ablative techniques might be used, each one with its own specific characteristics that should be taken into account in order to minimize the risk of complications. Moreover, the application of some protective manoeuvres, such as hydrodissection, gas insufflation, external compression, device bending and retrograde pyeloperfusion are useful to overcome these limitations. A good knowledge of differences among ablative techniques, optimal room setting and image guidance, and of possible protective manoeuvre is of paramount importance for a safe and effective application of image guided ablation to renal tumours.

Thus, in the present paper we offer an overview of the most frequently used ablative techniques, the best image guidance setting and of the most important protective manoeuvres that can be applied to image-guided thermal ablation of renal tumours, also presenting some didascalic cases.

\section{Ablative techniques}

The most widely used ablative techniques used to treat renal tumours are cryoablation, radiofrequency ablation, and microwave ablation $[9,26-41]$.

With cryoablation, repeated freeze-thaw cycles determine extracellular and intracellular ice formation with subsequent injury to cell membranes [26-28]. Cryoablation provide good visualization of the ice ball with both US and CT, which facilitates precise control of the procedure. Furthermore, as ice forming during the ablation firmly sticks to the surrounding tissues, it is possible to perform a gentle torqueing in order to displace the tumour from sensitive structures. Finally, as with cryoablation, the collagenous architecture is preserved, this technique appears to be ideal in tumours close to the calyx, as it might reduce the risk of fistula [29]. On the contrary, as cryoablation does not provide the "coagulative effect", this technique is burdened by an higher bleeding risk than other techniques [30-32].

With radiofrequency an alternating current determines ionic friction that leads to slow heat generation, with subsequent protein denaturation, blood coagulation, and coagulative necrosis [33, 34]. RFA determines also blood coagulation, thus reducing the bleeding risk in comparison with cryoablation [35]. Moreover, with a dedicated umbrella-shaped device it is possible to stick the electrode to the tissue. One of the most important limitations of RFA is represented by the loss of heat occurring close to vessels due to the blood flow (heat sink effect). However, heat propagation from the tip of the electrode might determine injury to close sensitive structures [37, 38].

With the microwave technique the ablative antenna generates an electromagnetic radiation that produces oscillation of water molecules with formation of frictional heating, achieving very high temperature in very short time, with larger and faster ablations [39]. This technique seems to be less affected by the heat sink effect that limits radiofrequency. However, as temperatures higher than with radiofrequency can be rapidly obtained, particular caution should be used for tumours abutting the renal sinus, as urine boiling can be fast obtained with subsequent damage on the collecting system $[40,41]$.

\section{Operating room setting, optimal image guidance, and ideal patient management}

Several imaging modalities can be used for guiding percutaneous tumour ablation, the two most widely used being US and CT. US is a radiation-free imaging modality, providing high-resolution real-time imaging, allowing for non-axial imaging, and for continuous monitoring of the different phases of the treatment. Immediate post-treatment evaluation with contrast-enhanced US (CEUS) can also be performed [23]. However, US is burdened by limitations in the case of obese patients, presence of air (e.g. intestinal loops), and often is lacking in contrast resolution particularly in cases of isoechoic renal tumours. Conversely, CT provides a larger field of view and a better visualization of renal tumours and structures containing air. However, CT requires use of ionizing radiation, provides mainly an axial view, and contrast media usage has to be cautiously applied. Thus, ideally, both modalities should be available in the operating theater. Systems that allow for the acquisition of CT images and real-time fusion with US seems to be extremely beneficial for image guided tumour ablation, allowing for merging the advantages of both the two imaging modalities and overcoming their limitations $[22,23]$. These types of systems have been already applied to the treatment of liver tumours, even for liver lesions completely invisible at US [22]. In renal ablation, such techniques provide evident advantages in the identification of the lesion, which is often not conspicuous at US. At the same time, the possibility of controlling in real time the needle insertion with US, with constant reference to a co-registered CT, enhances the safety of the procedure. However, since the kidney is highly mobile, displacement of the organ during the procedure might occur, reducing the reliability of the fused $\mathrm{CT}$ images. Thus, fusion imaging cannot be used as the sole method of guidance, and US should always be considered the reference for device insertion. Two cases are shown in Figs. 1 and 2.

Particularly helpful is to perform renal ablations under general anesthesia. General anesthesia allows for avoiding 
Fig. 1 Treatment of a right renal tumour with the application of US/CT fusion imaging. a Contrast enhanced CT demonstrating a right renal tumour (arrow). b needle insertion was performed with fusion of real-time US with the preacquired CT that allowed the precise positioning of the microwave antenna (arrowhead) at the level of the tumour (arrow). c CT acquisition immediately after antenna insertion confirmed the correct positioning of the device (arrow) in the desired position. $\mathbf{d}$ contrast enhanced CT $24 \mathrm{~h}$ after treatment demonstrated the correct ablation of the tumour (arrow)
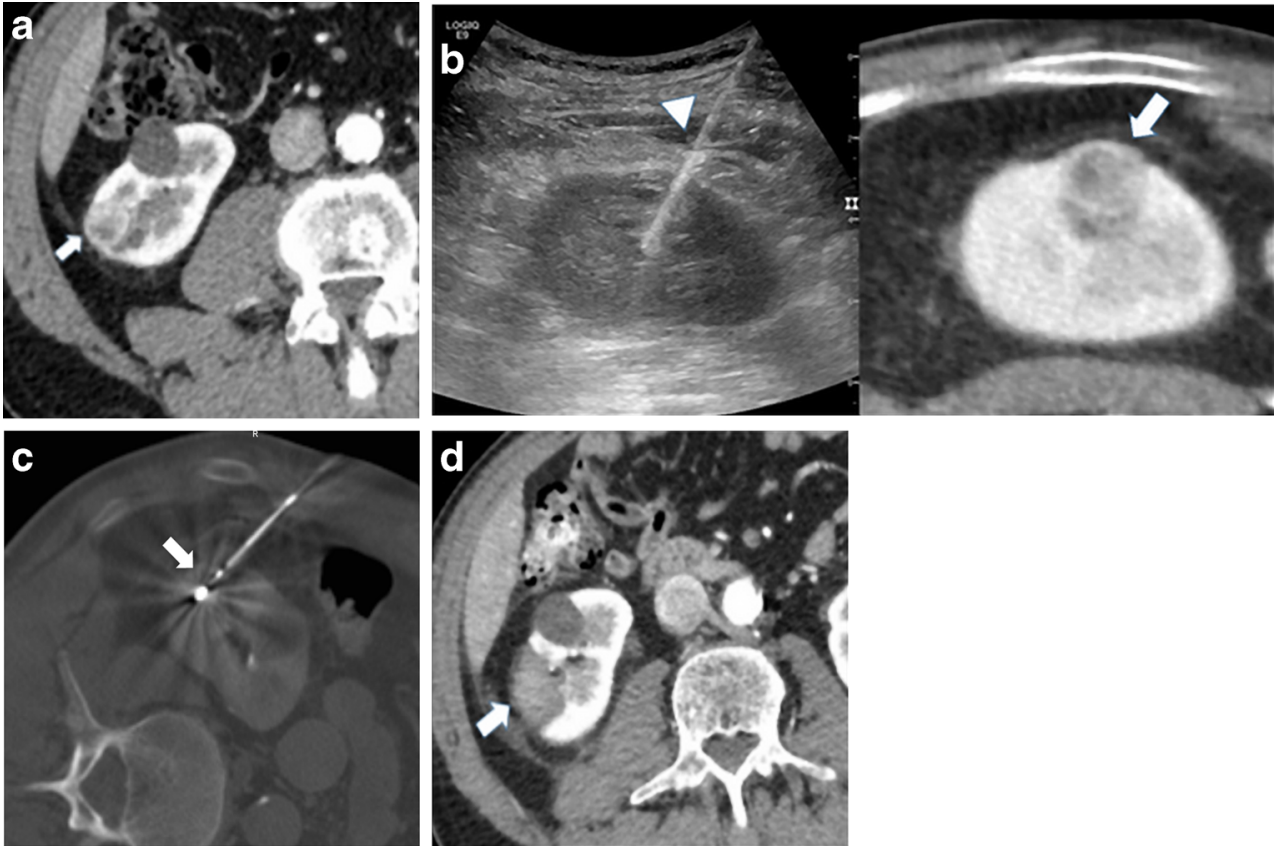

patients' movements during the procedure and even achieves a controlled breath-hold that enhances the targeting of the tumour and decrease the risk of unintended puncture of undesired structures.

After the procedure it is always recommended to perform a contrast enhanced CT to control for immediate result and eventual presence of complications.
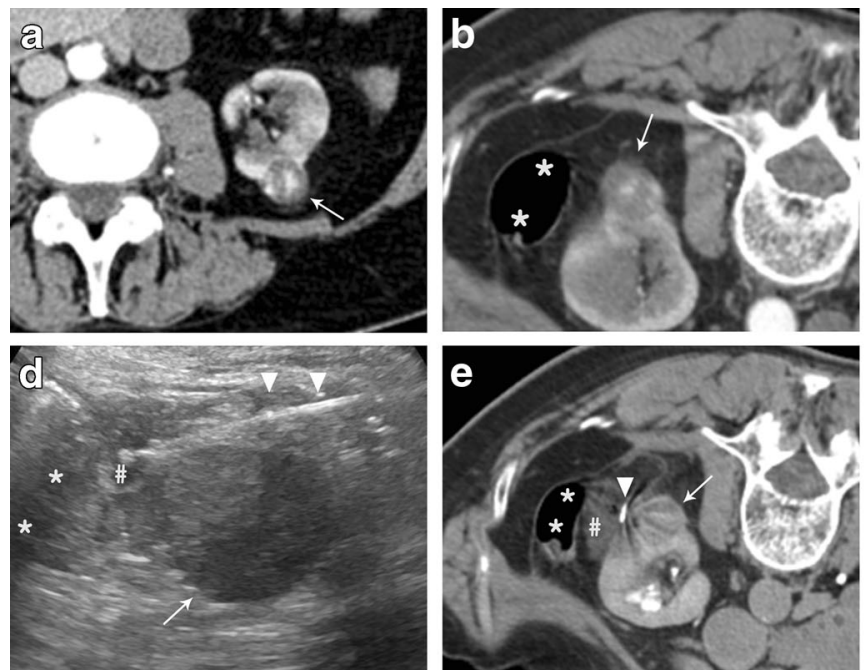

Fig. 2 Microwave ablation of a left posterior renal cell carcinoma close to the colon with hydrodissection. a Contrast enhanced CT demonstrating a left posterior renal cell carcinoma (white arrow) to be treated with percutaneous thermal ablation. b Contrast enhanced CT performed the day of the procedure. To achieve a safe path to the tumour the patient is placed in prone position with external compression. In this position, the colon (asterisks) appears to be close to the tumour to be treated (white arrow). $\mathbf{c}$ fusion of contrast enhanced CT and real-time US allowed for the identification of the tumour to be treated with US (white arrow $=t u$ mour; asterisks $=$ colon $)$. $\mathbf{d}$ under US guidance a small spinal needle

\section{Patient positioning and external compression}

Patients' position change might be sometimes enough to obtain a sufficient distance between the tumour and the surrounding structure to perform a safe ablation. For this purpose, careful planning, and application of dedicated devices such as vacuum mattress are of paramount importance. A simulation
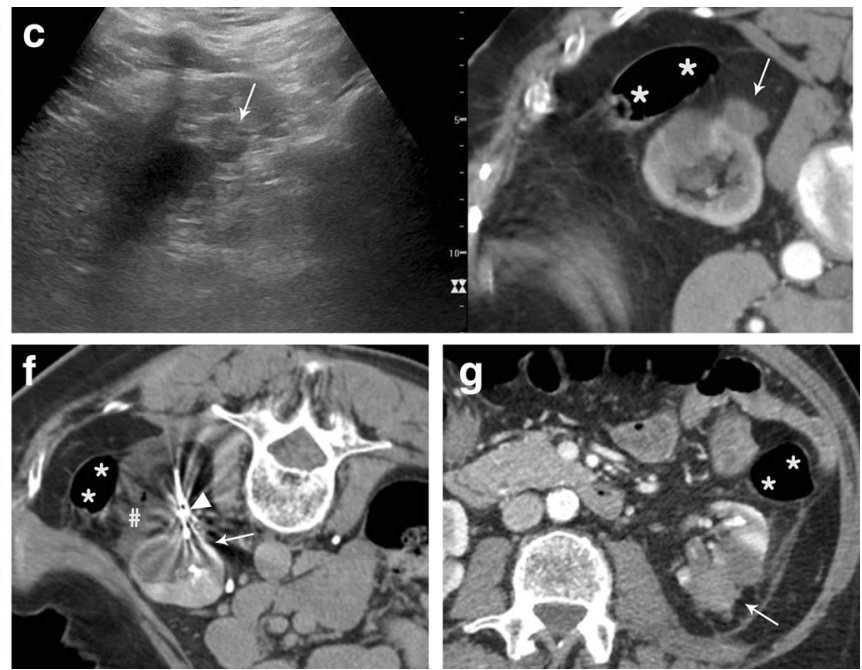

(arrowheads) is placed in between the tumour (white arrow) and colon (asterisks) and fluid (hash) is injected. e A CT scan performed after fluid (hash) injection confirmed the correct displacement of the colon (asterisks) from the target tumour (white arrow) (arrowhead $=$ spinal needle). $\mathbf{f}$ CT scan demonstrating the insertion of the microwave antenna (arrowhead) into the renal tumour (white arrow) (asterisks $=$ colon; hash $=$ injected fluid . $\mathbf{g}$ Contrast-enhanced CT performed the day after treatment demonstrating the complete ablation of the renal tumour (white arrow)without complications $($ asterisks $=$ colon $)$ 
can be made performing $\mathrm{CT}$ in different positions before the procedure. This can be done the same day of the procedure or some days in advance, changing the position of the patient up until the identification of the best and easiest trajectory for the ablative device.

\section{Hydrodissection}

Sensitive structures close to the target tumour may be displaced by injecting different substances in between. In particular, when a radiofrequency ablation with hydrodissection is planned, saline solution should be avoided because of its high electrical conductivity, and other fluid solution, such as glucose solution, have to be used. To perform hydrodissection a small needle is advanced between the tumour itself and the structure to be displaced. Generally, the instillation of $135-150 \mathrm{~cm}^{3}$ might be enough to displace adjacent bowel loops by about 2.1-2.5 cm [42]. Imaging is generally repeated after injection of the initial bolus of fluid to confirm deposition into the desired location. The needle can be left in place for subsequent instillation during thermal ablation [43]. Two cases are shown in Figs. 2 and 3.

\section{Gas insufflation}

Some authors applied injection of normal air [44], while others reported the use of carbon dioxide $(\mathrm{CO} 2)$ for organ displacement $[45,46]$. CO2 seems to be particularly useful, as it is quickly reabsorbed by the body and eliminated by respiration. $\mathrm{CO} 2$ has a low thermal conductivity, and large volumes can be safely injected.

Because of its nature, $\mathrm{CO} 2$ cannot be seen with US, thus, after careful needle placement in the desired position and after $\mathrm{CO} 2$ injection, the ablation procedure is often followed by $\mathrm{CT}$ imaging $[45,47]$. Since it is lighter than fluid, CO2 tends to diffuse anteriorly, and thus $\mathrm{CO} 2$ injection appears to be particularly useful to achieve displacement of structures that are located anteriorly to the tumour to be treated. A case is shown in Fig. 4.

\section{Electrode torqueing}

This technique can be used mainly with umbrella-shaped radiofrequency devices and with cryoablation. The tip of the ablation device is anchored into the tumour, and small movements of the organ can be achieved by gentle traction. It can be used in adjunct to other methods, such as hydrodissection or gas insufflation, to increase the distance between the tumour and surrounding structures. Great caution has to be used, as forceful torqueing can potentially cause vascular or parenchymal injuries of the organ $[42,48]$. An example is shown in Fig. 4.

\section{Balloon interposition}

This is usually a second-line technique: after abdominal wall puncture with an 18 or $19 \mathrm{G}$ coaxial needle, a 0.035 -in. wire is placed trough the needle. A sheath is then advanced over the
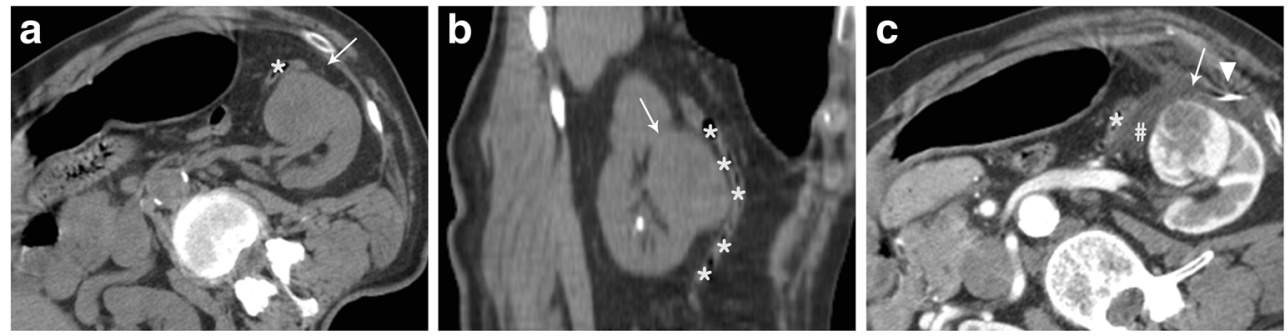
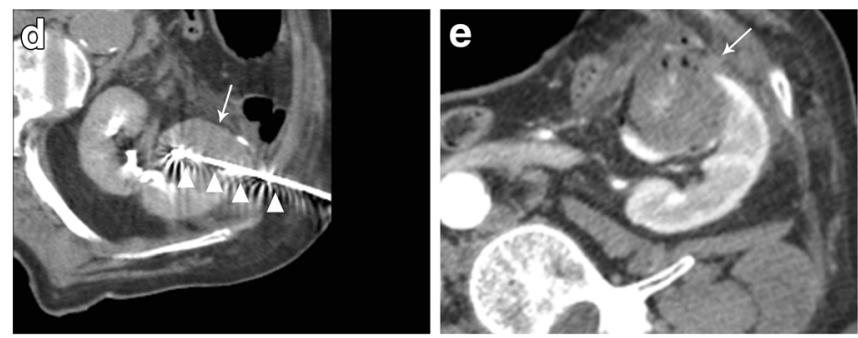

Fig. 3 Treatment of an anterior left renal tumour in close proximity with a bowel loop. a CT performed the day of treatment showing the close proximity of the tumour to be treated (white arrow) with a bowel loop (asterisks). Note the external compression to obtain the desired position of the patient for an easy access to the target tumour. b multiplanar reconstruction of the $\mathrm{CT}$ images showing the close proximity of the tumour (white arrow) with a bowel loop (asterisks). c A CT scan performed after fluid (hash) injection confirmed the correct displacement of the colon (asterisks) from the target tumour (white arrow) $($ arrowhead $=$ spinal needle). $\mathrm{d}$ CT scan demonstrating the insertion of the microwave antenna (arrowhead) into the renal tumour (white arrow). e Contrast-enhanced CT performed immediately after treatment demonstrating the complete ablation of the renal tumour (white arrow) without complications 
Fig. 4 Treatment of a right renal tumour with image guided thermal ablation with the assistance of $\mathrm{CO} 2$ injection. a contrast enhanced CT

demonstrating an anterior right renal tumour close to the colon (arrow). b patient was positioned in lateral decubitus and a small needle was inserted in between the tumour and the colon (arrow). c $\mathrm{CO} 2$ was injected through the small needle (arrow) in order to achieve colon displacement. $\mathbf{d}$ an umbrella-shaped radiofrequency electrode (arrow) was inserted into the tumour from the opposite site of the colon, and slight traction made in order to displace the organ. e a contrast enhanced $\mathrm{CT}$ performed $24 \mathrm{~h}$ after the ablation demonstrated good ablation of the tumour (arrow) without complications
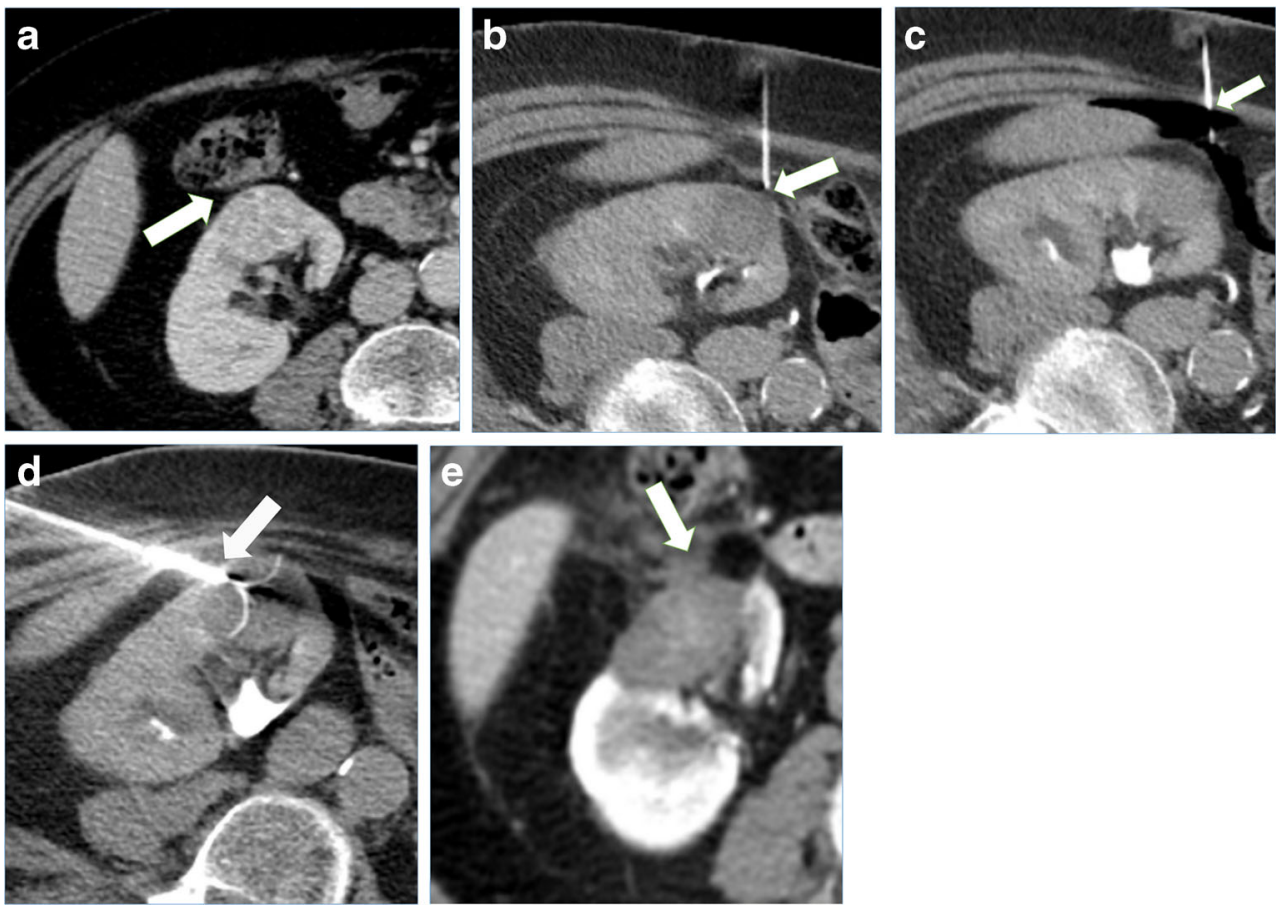

wire, and a balloon is advanced over the wire and trough the sheath. Once the position is adjusted under image guidance, the balloon is expanded completely $[49,50]$.

\section{Cooled pyeloperfusion}

In order to protect the collecting system from thermal damage, perfusion of the system with cold fluid solution can be performed. For this purpose, a retrograde ureteral 6 Fr single $\mathrm{J}$ catheter is placed before the ablation, and refrigerated solution is infused during the treatment. A small catheter is used in order to facilitate the water circulation into the renal pelvis. The ureteral single $\mathrm{J}$ is connected to a three-way stopcock, one way connected to the cold fluid bag and another to an empty collecting bag. Pyeloperfusion is performed intermittently by opening and closing the three-way stopcock [51]. A case is shown in Fig. 5. The catheter is left in place, secured to a

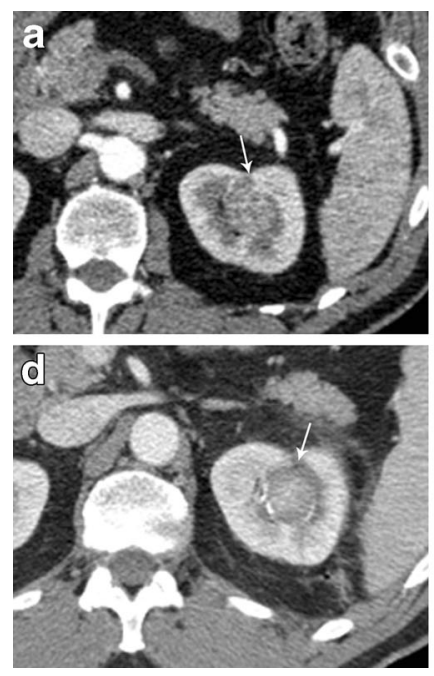

Fig. 5 Treatment of a left kidney central tumour with renal sinus extension. a contrast enhanced CT demonstrating a centrally located tumour (white arrow) with extension in close proximity of the renal sinus. b retrograde pyeloperfusion was performed through a single $\mathrm{j}$ stent (arrowheads) placed endoscopically the day of the ablation. c CT scan after insertion on a radiofrequency electrode (arrowheads) into the
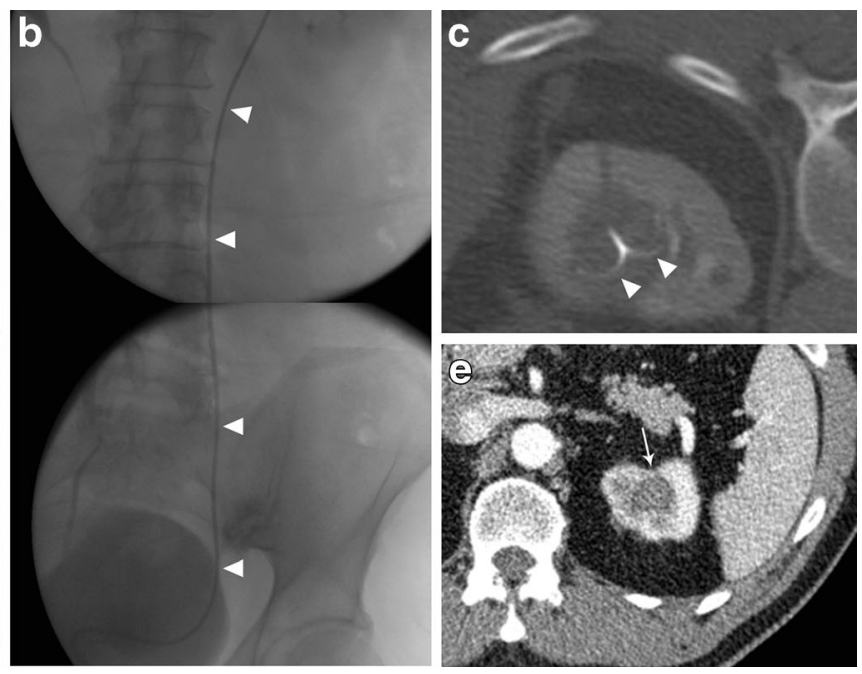

tumour. $\mathbf{d}$ contrast enhanced $\mathrm{CT}$ performed immediately after the ablation demonstrated the complete ablation of the tumour (white arrowhead) without complications. e Contrast enhanced CT 2 years after the ablation demonstrating complete ablation with tumour shrinkage and no complications 
bladder catheter, up to the day after the procedure. In cases where a fistula is demonstrated at subsequent 24 -h control, the catheter is left in place for a number of days and removed after subsequent imaging control and demonstration of resolution.

\section{Conclusions}

During the last few years, percutaneous thermal ablation has become a widespread alternative to nephrectomy and nephron sparing surgery thanks to the good clinical results, low invasiveness, low morbidity and rapid patient recovery.

Although percutaneous thermal ablation is considered safe, it can be complicated with unintended thermal injury to the surrounding structures, such as bowel loops, nerves, or the urinary collecting system.

Interventional radiologists who perform renal thermal ablation should have a fully equipped operating theater, possibly including CT, US, and a system for fusion imaging, and they should be familiar with all the ablative techniques and protective manoeuvres that can be applied to maximize the result and reduce complications.

Open Access This article is distributed under the terms of the Creative Commons Attribution 4.0 International License (http:// creativecommons.org/licenses/by/4.0/), which permits unrestricted use, distribution, and reproduction in any medium, provided you give appropriate credit to the original author(s) and the source, provide a link to the Creative Commons license, and indicate if changes were made.

\section{References}

1. Hancock JB, Georgiades CS (2016) Kidney cancer. Cancer J. 22: 387-392

2. Mirzaei M, Pournamdar Z, Salehiniya H (2015) Epidemiology and trends in incidence of kidney cancer in Iran. Asian Pacific J Cancer Prev 16:5859-5861

3. Chow W, Dong L, Devesa S (2010) Epidemiology and risk factors for kidney cancer. Nat Rev Urol 7:245-257

4. Herr H (2005) A history of Partial nephrectomy for renal tumors. J Urol 173:705-708

5. Pierorazio PM, Johnson MH, Patel HD et al (2016) Management of Renal Masses and Localized Renal Cancer. Comp Eff Rev 167:120

6. Ljungberg B, Cowan NC, Hanbury DC et al (2010) EAU guidelines on renal cell carcinoma: the 2010 update. Eur Urol 58:398-406

7. Sartori S, Tombesi P, Di Vece F (2016) Thermal ablation in colorectal liver metastases: lack of evidence or lack of capability to prove the evidence? World J Gastroenterol 22:3511

8. Ridge CA, Solomon SB (2015) Percutaneous ablation of colorectal lung metastases. J Gastrointest Oncol 6:685-692

9. Mauri G, Cova L, Ierace T et al (2016) Treatment of metastatic lymph nodes in the neck from papillary thyroid carcinoma with percutaneous laser ablation. Cardiovasc Intervent Radiol 39: $1023-1030$
10. Goldberg SN, Solbiati L (2016) Percutaneous laser ablation of metastatic lymph nodes in the neck from papillary thyroid carcinoma : preliminary results. 98:1203-1207

11. Gervais DA, McGovern FJ, Arellano RS et al (2005) Radiofrequency ablation of renal cell carcinoma: part I, indications, results, and role in patient management over a 6-year period and ablation of 100 tumors. Am J Roentgenol 185:64-71

12. Zagoria RJ, Traver MA, Werle DM et al (2007) Oncologic efficacy of CT-guided percutaneous radiofrequency ablation of renal cell carcinomas. Am J Roentgenol 189:429-436

13. Uppot RN, Silverman SG, Zagoria RJ et al (2009) Imaging-guided percutaneous ablation of renal cell carcinoma: a primer of how we do it. Am J Roentgenol 192:1558-1570

14. Yin X, Cui L, Li F et al (2015) Radiofrequency ablation versus Partial nephrectomy in treating small renal tumors: a systematic review and meta-analysis. Med 94:e2255

15. Potretzke AM, Larson JA, Bhayani SB (2015) Re: R. Houston Thompson, tom Atwell, grant Schmit, et al. comparison of Partial nephrectomy and percutaneous ablation for cT1 renal masses. Eur Urol 2015;67:252-9. Eur Urol 67:e19-e20

16. Gervais DA, McGovern FJ, Wood BJ et al (2000) Radio-frequency ablation of renal cell carcinoma: early clinical experience. Radiology 217:665-672

17. Ahmed M, Brace CL, Lee FT, Goldberg SN (2011) Principles of and advances in percutaneous ablation. Radiology 258:351-369

18. Jasinski M, Siekiera J, Chlosta P et al (2011) Radiofrequency ablation of small renal masses as an alternative to nephron-sparing surgery: preliminary results. Wideochirurgia i inne Tech małoinwazyjne $=$ Videosurgery other miniinvasive Tech $/$ Kwart Pod patronatem Sekc Wideochirurgii TChP oraz Sekc Chir Bariatrycznej TChP 6:242-245

19. Frey GT, Sella DM, Atwell TD (2015) Image-guided renal intervention. Radiol Clin N Am 53:1005-1019

20. Hines-Peralta A, Goldberg SN, Novick A et al (2004) Review of radiofrequency ablation for renal cell carcinoma. Clin Cancer Res $10: 6328 \mathrm{~s}-6334 \mathrm{~s}$

21. Li W, Bai Y, Wu M, et al. (2016) Combined CT-guided radiofrequency ablation with systemic chemotherapy improves the survival for nasopharyngeal carcinoma with oligometastasis in liver : propensity score matching analysis

22. Mauri G, Cova L, De Beni S et al (2014) Real-time US-CT/MRI image fusion for guidance of thermal ablation of liver tumors undetectable with US: results in 295 cases. Cardiovasc Intervent Radiol. doi:10.1007/s00270-014-0897-y

23. Mauri G (2015) Expanding role of virtual navigation and fusion imaging in percutaneous biopsies and ablation. Abdom Imaging 40:3238-3239

24. Iannuccilli JD, Dupuy DE, Beland MD, et al. (2015) Effectiveness and safety of computed tomography-guided radiofrequency ablation of renal cancer: a 14-year single institution experience in 203 patients. Eur Radiol 1656-1664. doi:10.1007/s00330-015-4006-7

25. Andersson M, Hashimi F, Lyrdal D et al (2015) Improved outcome with combined US/CT guidance as compared to US guidance in percutaneous radiofrequency ablation of small renal masses. Acta Radiol 56:1519-1526

26. Cazzato RL, Garnon J, Ramamurthy N et al (2016) Percutaneous image-guided cryoablation: current applications and results in the oncologic field. Med Oncol 33:1-16

27. Georgiades CS, Rodriguez R (2014) Efficacy and safety of percutaneous cryoablation for stage $1 \mathrm{~A} / \mathrm{B}$ renal cell carcinoma: results of a prospective, single-arm, 5-year study. Cardiovasc Intervent Radiol 37:1494-1499

28. Shyn PB, Mauri G, Alencar RO, et al. (2014) Percutaneous Imaging-Guided Cryoablation of Liver Tumors: Predicting Local Progression on 24-Hour MRI. AJR Am J Roentgenol 1-11. doi:10. 2214/AJR.13.10747 
29. Baust JG, Gage AA, Bjerklund Johansen TE, Baust JM (2014) Mechanisms of cryoablation: clinical consequences on malignant tumors. Cryobiology 68:1-11

30. Buy X, Lang H, Garnon J et al (2013) Percutaneous renal cryoablation: prospective experience treating 120 consecutive tumors. Am J Roentgenol 201:1353-1361

31. Kapoor A, Touma NJ, El Dib R (2013) Review of the efficacy and safety of cryoablation for the treatment of small renal masses. Can Urol Assoc J 7:E38-E44

32. Niu L-Z, Li J-L, Xu K-C (2014) Percutaneous Cryoablation for liver cancer. J Clin Transl Hepatol 2:182-188

33. Kelly EF, Leveillee RJ (2016) Image guided radiofrequency ablation for small renal masses. Int J Surg 36:525-532

34. Balageas P, Cornelis F, Le Bras Y et al (2013) Ten-year experience of percutaneous image-guided radiofrequency ablation of malignant renal tumours in high-risk patients. Eur Radiol 23:1925-1932

35. Pantelidou M, Challacombe B, McGrath A et al (2016) Percutaneous radiofrequency ablation versus robotic-assisted Partial nephrectomy for the treatment of small renal cell carcinoma. Cardiovasc Intervent Radiol 39:1595-1603

36. Mauri G, Sconfienza LM, Pescatori LC et al (2017) Technical success, technique efficacy and complications of minimally-invasive imaging-guided percutaneous ablation procedures of breast cancer: a systematic review and meta-analysis. Eur Radiol. doi:10.1007/ s00330-016-4668-9

37. Su MZ, Memon F, Lau HM et al (2016) Safety, efficacy and predictors of local recurrence after percutaneous radiofrequency ablation of biopsy-proven renal cell carcinoma. Int Urol Nephrol 48: $1609-1616$

38. de Menezes MR, Viana PCC, Yamanari TR et al (2016) Safety and feasibility of radiofrequency ablation for treatment of Bosniak IV renal cysts. Int Braz J Urol 42:456-463

39. Cornelis FH, Marcelin C, Bernhard J-C (2016) Microwave ablation of renal tumors: a narrative review of technical considerations and clinical results. Diagn Interv Imaging. doi:10.1016/j.diii.2016.12. 002

40. Singla N, Gahan J (2016) New technologies in tumor ablation. Curr Opin Urol 26:248-253
41. Shin BJ, Chick JF, Stavropoulos SW (2016) Contemporary status of percutaneous ablation for the small renal mass. Curr Urol Rep 17: 23

42. Ginat DT, Saad WE (2010) Bowel displacement and protection techniques during percutaneous renal tumor thermal ablation. Tech Vasc Interv Radiol 13:66-74

43. Arellano RS, Garcia RG, Gervais DA, Mueller PR (2009) Percutaneous CT-guided radiofrequency ablation of renal cell carcinoma: efficacy of organ displacement by injection of 5\% dextrose in water into the retroperitoneum. Am J Roentgenol 193:16861690

44. Ginat DT, Saad W, Davies M et al (2009) Bowel displacement for CT-guided tumor radiofrequency ablation: techniques and anatomic considerations. J Endourol 23:1259-1264

45. Buy X, Tok C-H, Szwarc D et al (2009) Thermal protection during percutaneous thermal ablation procedures: interest of carbon dioxide dissection and temperature monitoring. Cardiovasc Intervent Radiol 32:529-534

46. Kariya S, Tanigawa N, Kojima $\mathrm{H}$ et al (2005) Radiofrequency ablation combined with $\mathrm{CO} 2$ injection for treatment of retroperitoneal tumor: protecting surrounding organs against thermal injury. AJR Am J Roentgenol 185:890-893

47. Laeseke PF, Sampson LA, Brace CL et al (2006) Unintended thermal injuries from radiofrequency ablation: protection with $5 \% \mathrm{dex}-$ trose in water. Am J Roentgenol 186:249-254

48. Park BK, Kim CK (2008) Using an electrode as a lever to increase the distance between renal cell carcinoma and bowel during CTguided radiofrequency ablation. Eur Radiol 18:743-746

49. Tsoumakidou G, Buy X, Garnon J et al (2011) Percutaneous thermal ablation: how to protect the surrounding organs. Tech Vasc Interv Radiol 14:170-176

50. Kam AW, Littrup PJ, Walther MM et al (2004) Thermal protection during percutaneous thermal ablation of renal cell carcinoma. $\mathrm{J}$ Vasc Interv Radiol 15:753-758

51. Rouvière $\mathrm{O}$, Badet L, Murat FJ et al (2008) Radiofrequency ablation of renal tumors with an expandable multitined electrode: results, complications, and pilot evaluation of cooled pyeloperfusion for collecting system protection. Cardiovasc Intervent Radiol 31: 595-603 